\title{
Cross-talks between natural killer cells and distinct subsets of dendritic cells
}

\section{Guido Ferlazzo ${ }^{1,2}$ and Barbara Morandi ${ }^{3}$}

1 Department of Human Pathology, University of Messina, Messina, Italy

${ }^{2}$ Cellular Therapy Program, University Hospital Policlinico G. Martino, Messina, Italy

${ }^{3}$ Department of Experimental Medicine, University of Genoa, Genoa, Italy

\section{Edited by:}

Massimo Vitale, IRCCS A.O.U. San Martino-IST, Italy

\section{Reviewed by:}

Evelyn Ullrich, Goethe University

Frankfurt, Germany

Mariella Della Chiesa, University of

Genoa, Italy

\section{${ }^{*}$ Correspondence:}

Barbara Morandi, Department of Experimental Medicine, University of Genoa, L.Go R. Benzi 10, Genoa 16132, Italy

e-mail: morandibarb@yahoo.it
In recent years, the essential role of bi-directional cross-talk between natural killer (NK) and dendritic cells (DC) during immune responses has been clearly elucidated. In particular, this cross-talk results in the development of an efficient innate response, through DC-mediated NK cell activation, and a potent adaptive immune response, through NK-mediate DC editing and maturation. Recently, some novel human DC subsets have been identified: migratory DCs in afferent lymph and draining lymph nodes; CLEC9A ${ }^{+} / \mathrm{BDCA}^{+}(\mathrm{CD} 141) \mathrm{DCs}$ in interstitial dermis, liver, lung; inflammatory DCs in several inflammatory fluids. At the same time, it has been shown that also human NK cells are present in these compartments. Here, we will review the most recent findings on NK/DC cross-talk and we will discuss the necessity of acquiring more complete knowledge about these interactions in view of the new information available on both DC and NK cell subsets.

Keywords: natural killer cells, dendritic cells, humans, cross-priming, Th1 cells

\section{INTRODUCTION}

Natural killer (NK) cells were originally identified as lymphocytes that can spontaneously kill certain tumor target cells in the absence of previous stimulation in vivo or in vitro (1). NK cell activation results from the balance of signals produced by activating (2) and inhibitory (3) receptors. CD16 (FcRIIIa) is one of these activating NK cell receptors and binds human immunoglobulins, therefore mediating antibody-dependent cellular cytotoxicity (ADCC) of opsonized target cells. However, many other innate receptors acting upstream of the adaptive immunity have also been discovered. Among these, the first to be identified were natural cytotoxicity receptors (NCR) termed NKp46, NKp44, and NKp30 (2). NK cells also express additional activating receptors such as NKG2D and DNAM-1, which are partially shared with T lymphocytes, 2B4, NTBA, and NKp80 which promote NK cell triggering during the process of natural cytotoxicity (4). Activating NK cell signals are therefore mediated by several receptors and it is widely accepted that the ligands for NK cell activating receptors are mainly expressed on "stressed" cells, hence favoring killing of both tumor or infected cells (4). Nevertheless, an important exception to this rule is the ability of NK cells to kill normal autologous dendritic cells (DCs) $(5,6)$ as well as other immune cells such as macrophages and $\mathrm{T}$ lymphocytes (7-9).

On the other hand, human NK cells also express different inhibitory receptors recognizing human leukocyte antigen (HLA) class I molecules: killer immunoglobulin (Ig)-like receptors (KIRs) are specific for allelic determinants of HLA class I molecules, the Ig-like transcript (ILT)-2 receptor is characterized by a specificity for different HLA class I molecules, and CD94/NKG2A recognizes non-classical HLA class I molecules HLA-E (4). Therefore, cells that have lost HLA class I molecules such as tumor or virus-infected cells fail to deliver inhibitory signals to NK cells.
Peripheral blood NK cells in humans can be divided into two main subsets according to CD56 expression, namely CD56 ${ }^{\mathrm{dim}}$ and CD56 $6^{\text {bright }}$, characterized by distinct functional and phenotypic properties. It has been established that a division of labor exists among these two subsets: CD56 ${ }^{\mathrm{dim}}$, expressing CD16, KIRs, and high levels of perforin, have enhanced killing activity, whereas CD56 ${ }^{\text {bright }}$ cells, characterized by low levels of perforin and CD16, no KIRs and high expression of NKG2A, can secrete large amounts of cytokines (e.g., IFN- $\gamma$, GM-CSF, TNF) but not kill target cells. Nevertheless, with the appropriate stimulus, also CD56 ${ }^{\mathrm{dim}} \mathrm{CD} 16^{+}$ NK cells are abundant cytokine producers $(10,11)$.

In the last few years, the functional links between NK cells and DCs have been widely investigated and different studies have demonstrated that reciprocal activations ensue upon NK/DC interactions. More recently, the anatomical sites where these interactions take place have started to be identified together with the related cell subsets involved.

Dendritic cells were identified for the first time in 1973 by Ralph Steinman as accessory cells in mice spleen. During the last two decades, it has been established that DCs are professional antigen presenting cells (APCs), uniquely skilled to attract and activate $\mathrm{CD}^{+}{ }^{+}$and $\mathrm{CD} 8^{+} \mathrm{T}$ cells. Most of our knowledge on DCs comes from studies of blood and skin DCs. However, improvements of both flow cytometric and genomic approaches have recently allowed the identification of several distinct subsets of DCs. Despite their heterogeneity, there are some features common to all DC subsets, both in mice and humans. Immature DCs act like sentinels efficiently sampling antigenic material. Upon pathogen encounter, they undergo a complex maturation process that leads to professional antigen presentation, cytokine production, and $\mathrm{T}$ cell stimulatory capacities. During the maturation process, they upregulate distinct molecules on their surface 
such as major histocompatibility complex (MHC) class II, CD80, CD83, CD86, and CD40 essential for antigen presentation and interaction with T cells; at the same time, they migrate from the periphery to secondary lymphoid organs (SLO) where they can induce $\mathrm{CD}^{+}$and $\mathrm{CD}^{+}{ }^{+} \mathrm{T}$ cell response (12).

Two main populations of DCs have been described in humans: $\mathrm{BDCA}^{+}(\mathrm{CD} 303) / \mathrm{CD} 123^{+}$plasmacytoid DCs (pDCs) and myeloid DCs (mDCs) (13). The latter includes several subsets identified in distinct tissues, thus resulting in a high level of heterogeneity; peripheral blood contains two main DC subsets: $\mathrm{BDCA}^{+}{ }^{+}$CD1c) DCs and CLEC9A ${ }^{+} / \mathrm{BDCA}^{+}(\mathrm{CD} 141) \mathrm{DCs}(14$, 15); as they are both also present in lymph nodes and tonsils, they have been described as blood-derived lymphoid organ-resident DCs (14-17).

Besides peripheral blood, also the skin includes distinct and well-characterized DC subsets: the epidermis contains Langerhans cells (LCs) and the dermis at least three subsets: dermal CD1a ${ }^{+}$ DCs, dermal CD $14^{+}$DCs, and CLEC9A ${ }^{+} / \mathrm{BDCA}^{+}$DCs (18-20). All these DC subsets can migrate through the lymph to draining lymph nodes (21). Finally, in several inflammatory conditions such as atopic dermatitis, psoriasis, rheumatoid arthritis, and tumor ascites, a different DC subtype, referred to as "inflammatory DC," has lately been described (22). Transcriptomic analysis revealed that they likely derive from monocytes that differentiate at the site of inflammation. Interestingly, it has been recently suggested that, in inflamed tissues, CD56 ${ }^{\text {bright }} \mathrm{NK}$ cells may induce differentiation of monocytes into inflammatory DCs (23).

This broad heterogeneity corresponds to distinct specialized functions in terms of tissue distribution, cytokine release, antigen presentation, and regulation of $\mathrm{T}$ cell response. These different features of the distinct DC subsets will be reviewed here and discussed in the context of possible interactions of NK cells with different DC subsets.

\section{DISTRIBUTION OF HUMAN NK CELL SUBSETS}

In the last few years, it has become evident that NK cells are not exclusively found in peripheral blood and SLO but can populate different non-lymphoid tissues (24). In mice, where investigating NK cell localization is more straightforward than in humans, the presence of NK cells in many organs has been revealed (25) and distribution seems to be subset-specific, as different NK cell subsets showed organ-specific localizations. Lately, some light has also been shed regarding the distribution of human NK cells in solid tissues, showing that NK cells populate, and may re-circulate through most human peripheral tissues, and that organ-specific chemokine expression patterns can drive the homing of functionally distinct NK cell subsets to the various human body compartments, both at steady-state and pathology (26). In particular, CD56 $6^{\text {bright }} \mathrm{NK}$ cells selectively accumulate in several organs, including SLO, liver, visceral adipose tissues, and gastrointestinal tract. Moreover, in a large variety of human malignancies, CD56 ${ }^{\text {bright }}$ NK cells represent the majority of NK cells infiltrating the tumor. Recently, we have reported that seroma, an accrual of fluid subsequent to surgical procedures such as axillary lymph node dissection, represents an accumulation of afferent lymph, drained from upstream tissues during the interval of time needed for lymphatic vessels to re-anastomose with the efferent ducts (27). Seroma accumulates without major contamination by either surgery-induced exudate or leaky blood-derived cells, thus confirming the lymph-associated origin of the cells contained in seroma fluids (21). Interestingly, only CD $56^{\text {bright }} / \mathrm{CD} 16^{\text {low/neg }} / \mathrm{KIR}^{\text {neg }}$ non-cytotoxic NK cells were detectable in afferent lymph from seroma fluids and appear therefore able, similarly to naïve $\mathrm{T}$ cells, to re-circulate via afferent lymph. NK cells are also present in human efferent lymph (28) suggesting that they can re-circulate from solid tissues to peripheral blood through lymphatic circulation and SLO.

The evidence that CD56 $6^{\text {bright }} \mathrm{NK}$ cells are, in most solid tissues, more abundant than in peripheral blood (which contains only around $2 \%$ of human body total lymphocytes) $(29,30)$, suggests they might probably outnumber CD56 ${ }^{\mathrm{dim}} \mathrm{NK}$ cells in the human body. The functional role of such an abundant non-cytolytic, but cytokine-secreting, NK cell subset in solid organs remains to be fully clarified. Interestingly, it has been shown that human DCs primarily activate this NK cell subset (31) promoting IFN- $\gamma$ release and proliferation.

\section{DISTRIBUTION OF HUMAN DC SUBSETS}

Thanks to improvements in both flow cytometric and genomic techniques, it is now clearer and clearer that human DCs represent a heterogeneous cell population and that each DC subset is often characterized by specific functional properties. BDCA1 ${ }^{+}$ DCs have recently been described as the most potent human IL-12-producing APCs (32), suggesting a potential key role in promoting IFN- $\gamma$ release by NK cells, and therefore Th1 polarization. $\mathrm{CLEC} \mathrm{A}^{+} / \mathrm{BDCA}^{+}{ }^{+} \mathrm{DCs}$, originally identified in peripheral blood and lymph nodes, have recently been detected also in other human organs such as skin, liver, lung, and intestine, where they show a more mature phenotype compared to $\mathrm{CLEC} \mathrm{A}^{+} / \mathrm{BDCA}^{+}$DCs observed in either blood or lymph nodes, indicating that they may represent a mature stage of differentiation (18). Moreover, $\mathrm{CLEC} \mathrm{A}^{+} / \mathrm{BDCA}^{+}{ }^{+} \mathrm{DCs}$ are characterized by the peculiar ability to cross-present antigens from dead cells better than other DC subtypes (18) but they seem equally able to cross-present soluble antigens (33) when compared to other DCs. It can be hypothesized that different DC subsets need distinct TLR stimulation to efficiently cross-present exogenous antigens. Cross-presentation represents a key process for specific CTL response against most tumors and viruses that do not infect APCs. The antigen forms, as well as the activation signals received by DCs, are likely to be critical in determining the efficiency of cross-presentation. Moreover, it has been shown that $\mathrm{CLEC} 9 \mathrm{~A}^{+} / \mathrm{BDCA}^{+}{ }^{+} \mathrm{DCs}$ have the dual capacity to produce both IL-12 and type I IFN (34), thereby enabling both NK cell activation and Th1 polarization, which could be significant for a protective immune response against viral infections. In particular, type I IFN can enhance NK cell cytotoxicity while IL-12 promotes IFN- $\gamma$ secretion and Th1 polarization.

Dendritic cells in human skin also show distinct patterns of functional capabilities: dermal CD1a ${ }^{+}$DCs have been described as immature cells capable of inducing $\mathrm{T}$ cell response only upon stimulation, while in steady-state they might be tolerogenic (35). On the other hand, dermal CD14 ${ }^{+}$DCs seem to play a critical role in the regulation of humoral immunity and LC in the induction of CTL response (20). LCs also secrete IL-15 and are therefore potentially able to activate both $\mathrm{CD}^{+} \mathrm{T}$ cells and NK cells (36). 
In general, immature (non-activated) DCs act as sentinels in peripheral tissues; upon activation through danger signals they initiate the maturation process that allows them to migrate to lymph nodes via afferent lymph. In many experimental animal models, DCs have been shown to be able to continuously migrate from intestine or from skin to SLO $(12,37,38)$. Most recently, DCs in human afferent lymph have also been characterized (21). Besides dermal CD1a ${ }^{+}$DCs, dermal CD $14^{+}$DCs and LC, afferent lymph also includes CLEC9A ${ }^{+} / \mathrm{BDCA}^{+}{ }^{+} \mathrm{DCs}$ and $\mathrm{CD} 1 \mathrm{a}^{+} \mathrm{CD} 14^{+} \mathrm{DCs}$, the latter likely representing an immature stage of differentiation from $\mathrm{CD} 14^{+}$DCs to CD1a ${ }^{+}$DCs.

\section{NK CELL CROSS-TALK WITH DENDRITIC CELLS}

The cooperative interaction between DCs and NK cells plays a key role in triggering immune response against pathogens. This dialog results in a bi-directional activation and has effects also on the subsequent adaptive immune response, influencing the development of Th1 cells and CTLs, both essential for an effective anti-tumor and anti-viral immune response.

\section{DCs INDUCE NK CELL ACTIVATION}

Dendritic cells promote the release of cytokines by NK cells (mainly TNF and IFN- $\gamma$ ) and enhance NK cell proliferation and cytolytic activity. DC-mediated NK cell activation occurs mainly through the release of soluble factors (Figure 1) although cellto-cell contacts play a relevant role during NK/DC interaction, as better specified below.

It has been shown, in different mice models, that NK cell preactivation by DCs is required for an efficient immune response against viral infections (39-41) and tumors (42). A large variety of microbial stimulation and signaling via TLRs can induce DC

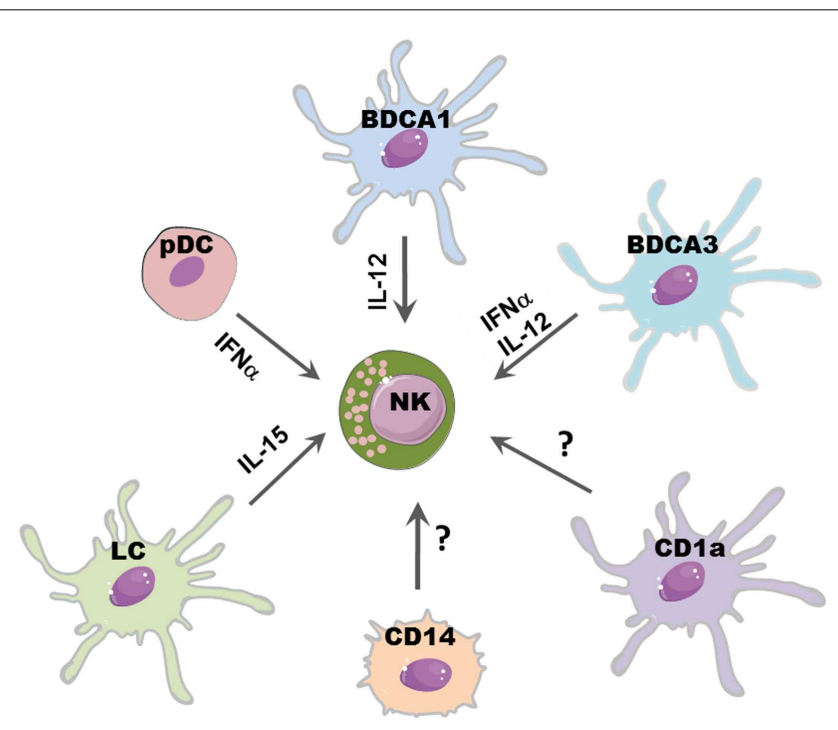

FIGURE 1 | DCs subsets may differently affect NK cell function. Distinct DC subsets reflect different capability to promote NK cell function: IL-15 released by $L C$ may promote NK cell proliferation; IL-12, mainly produced by $\mathrm{CLEC9A}^{+} / \mathrm{BDCA}^{+} \mathrm{DC}$ s and BDCA $1^{+} \mathrm{DCs}$, induces IFN- $\gamma$ release and subsequent Th1 polarization of T cells; NK cytolytic activity may be boosted by IFN- $\alpha$ secreted by pDCs and CLEC9A+/BDCA3 ${ }^{+}$DCs. maturation and secretion of several cytokines which can in turn activate NK cells. IL-12, mainly secreted by mDCs (in particular from BDCA1 ${ }^{+}$DCs), efficiently stimulate IFN- $\gamma$ secretion by NK cells. IL-18 can potentiate the effect of IL-12 by inducing the expression of IL-12R on NK cells. Moreover, IL-18 synergizes with IL-12 for enhancing NK cell cytolytic activity (43).

Also pDCs might activate NK cells, most likely via the release of type I IFN, which has been shown sufficient to boost NK cell cytotoxicity (44). Indeed, a protective NK cell response during infection with the murine cytomegalovirus (MCMV) was found to be type I IFN-dependent (45). Of note, the recently described $\mathrm{CLEC} \mathrm{A}^{+} / \mathrm{BDCA}^{+} \mathrm{DC}$ subset can also release high amounts of INF- $\alpha$, suggesting that, upon viral infection, they may play a key role in promoting NK cell cytotoxicity in peripheral tissues, such as skin, liver, lung, and intestine (34).

Another relevant cytokine for NK cell development and functions is IL-15, which is also produced by DCs. This cytokine can be presented by DCs via its binding to IL15R alpha or as transmembrane protein; it can stimulate NK cell proliferation, survival, and priming of protective NK cell response (44). In particular, it has been shown that LC can support NK survival via IL-15 (46). Besides the membrane-bound form of IL-15, it has been established that also other contact-dependent mechanisms are involved in NK-DC cross-talk. In general, the formation of stimulatory synapses between DCs and NK cells plays a critical role during NK cell activation induced by DC-derived cytokines, including IL-12 (47). Also, the interaction of CXC3CL1 expressed on DCs with CX3CR1 on NK cells results in IFN- $\gamma$ release by NK cells (48) and it has been shown that influenza virus-infected DCs can support IFN $-\gamma$ production by triggering the activating receptors NKp46 and NKG2D (49).

Most of the studies on NK/DC interactions in humans are based on DCs derived from monocytes, which are generated after several days of culture with different cytokines. On the other hand, the interactions between ex vivo isolated human DCs and NK cells have been poorly investigated so far and, despite the clear heterogeneity of human DC subsets, only peripheral blood DCs have, to some extent, been investigated (50-52). In these studies, it has been shown that both plasmacytoid and myeloid peripheral blood DCs are capable of activating NK cells, enhancing their cytolytic activity and inducing IFN- $\gamma$ release in response to influenza virus or dsRNA.

Among human NK cell subsets, CD56 ${ }^{\text {bright }}$ NK cells were found to be particularly responsive to activation by DCs (31, 53). Interestingly, they are enriched in SLO and in most solid tissues (26). Their presence in afferent lymph also suggests that they may re-circulate from peripheral solid tissues to SLO; thus, it is conceivable that, in vivo, NK-DC cross-talk may occur either in peripheral tissues or in lymph nodes, where, in both cases, NK cells can encounter distinct myeloid DC subsets. Recent reports indicate that DC heterogeneity may also correspond to the induction of different functions in $\mathrm{NK}$ cells: $\mathrm{BDCAl}^{+}$ DCs may be important for IL-12 secretion in SLO, favoring IFN $-\gamma$ secretion and consequent Th1 polarization of $\mathrm{T}$ cells; $\mathrm{CLEC}^{+} \mathrm{BDCA}^{+}{ }^{+} \mathrm{DCs}$ may be relevant in peripheral tissue where, upon virus infection, they can induce NK cytolytic activity by releasing IFN- $\alpha$. 
In conclusion, the activation of NK cells ensuing upon interaction with DCs has important consequences not only for the lysis of tumor or virus-infected cells, but it can also boost ongoing adaptive responses by the release of IFN- $\gamma$, which promotes type 1 polarization of T cells (Figure 2). Moreover, once activated, NK cells can edit DCs, by eliminating the more immature, allegedly tolerogenic DCs, as further discussed below. At the same time, NK cells can also shape adaptive immune responses by causing DC activation.

\section{NK CELLS INDUCE ACTIVATION AND EDITING OF DCs}

Activation of NK cells can occur via triggering of activating receptors by target cells or by stimulation of soluble factors released by accessory cells. Following activation, NK cells release large amounts of TNF and IFN- $\gamma$, which are known to affect DC maturation. TNF enhances the expression of costimulatory molecules on DCs and, synergizing with IFN- $\gamma$, contributes to DC production of IL-12 $(54,55)$. Moreover, exposure of NK cells to innate cytokines such as IL-12 and IL-18 (both released by mDCs) can promote Th1 polarization [Figure 2 and Ref. (56)]. INF- $\gamma$ can also induce the expression of a membrane-bound form of IL15 on DCs, thus sustaining both $\mathrm{T}$ and NK cell survival and activation (57).

Besides soluble factors, it has been shown that engagement of the NK activating receptor NKp30 can mediate DC maturation (58). Thus, recognition of target cells by NK cells can induce an additional mechanism of DC maturation, which might be particularly relevant in tumor immunity, where the absence of danger signals precludes DC maturation via the engagement of pattern recognition receptors $(59,60)$.

During initiation of an anti-viral or anti-tumor immune response, the microenvironment is influenced by a peculiar cytokine milieu, which includes cytokines released following NK cell activation $(61,62)$. It must be noted that NK cell triggering often occurs upstream of $\mathrm{T}$ cell activation, providing both a first line of defense and an early production of cytokine, critical for the subsequent development of the adaptive immune response. Although it is generally accepted that CTL response needs helper signals provided by $\mathrm{CD} 4^{+} \mathrm{T}$ cells, interactions occurring between DCs and NK cells can bypass these helper signals by leading to the production of IFN- $\gamma$, which, in turn, can stimulate IL-12 production by DCs, thus eventually leading to a protective CTL response $(57,63,64)$.

While the helper role of NK cells in inducing DC-mediated generation of Th1 polarized T cells and CTLs has been well documented, an issue not exhaustively elucidated so far is the ability of NK cells to promote DC cross-priming. Nevertheless, some reports suggest a role for NK cells in promoting antigen cross-presentation by DCs. It has been shown that DCs can take up dying cells killed by NK cells and present them on MHC class I molecules $(65,66)$. Obviously, NK cell ability to lyse virally infected or tumor cells could help uptake and cross-presentation of antigens by DCs but whether NK cells also play a direct role in favoring DC crosspresentation is still not clear. In a human in vitro system, it has

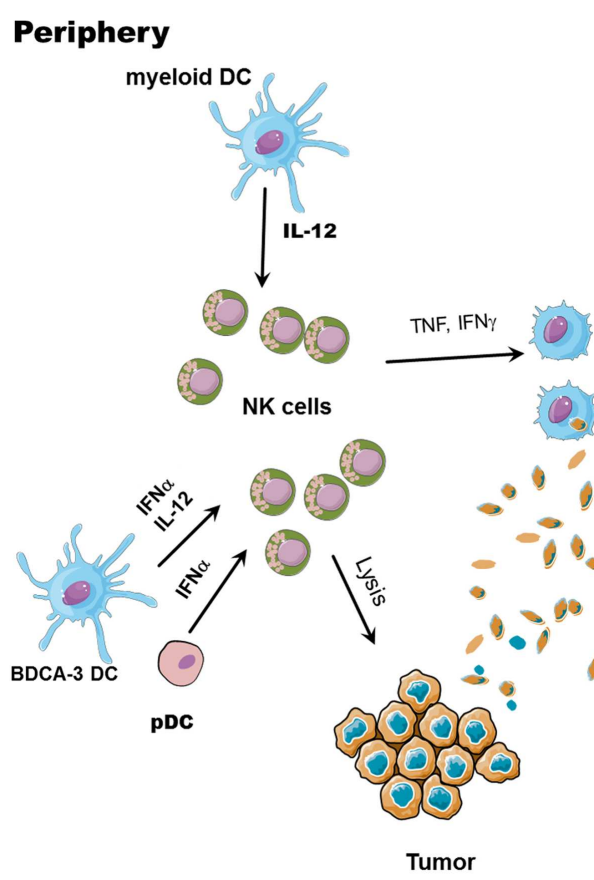

FIGURE 2 | NK/DC cross-talk. The interaction between NK cells and DCs results in reciprocal activation: mature DCs release cytokines able to promote NK cell activation (all myeloid mature DCs can produce IL-12 whereas pDCs and $\mathrm{CLEC9A}^{+} \mathrm{BDCA}^{+} \mathrm{DC}$ can release large amounts of IFN- $\alpha$ ); in turn, IFN- $\gamma$ released by activated NK cells promotes Th1 polarization and, together

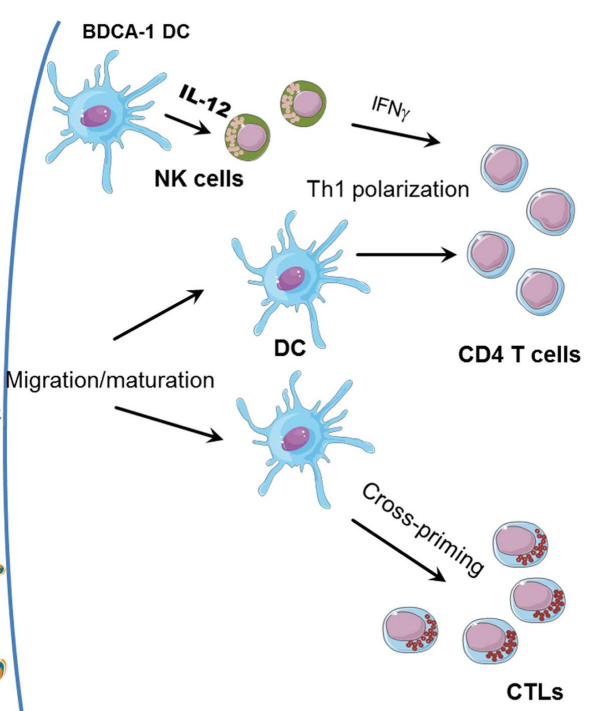

Lymphnode 
been demonstrated that cross-presentation of antigens to $\mathrm{CD} 8^{+}$ $T$ cells by DCs requires NK cells: capture of tumor cells and maturation status of DCs are not sufficient to induce cross-priming of $\mathrm{T}$ cells without further NK-mediated activation and IL-18 release (67). Moreover, the capability of mono-derived DCs, generated in the presence of IFN- $\alpha$ (IFN-DCs), to prime $\mathrm{CD}^{+}{ }^{+} \mathrm{T}$ cells against human tumor antigens is dependent on NK cells; NK cell removal indeed leads to generation of IFN-DCs with no priming activity of tumor Ag-specific T cells (68). In vivo, in a mice model of melanoma, tumor regression resulted from an immune cascade initiated by activated pDCs and involving NK cells, $\mathrm{mDCs}$, and $\mathrm{T}$ cells. It was shown that $\mathrm{CpG}$-activated pDCs can recruit NK cells at the tumor sites via chemokine production (CCL3, CCL4, and CCL5), and enhance their cytolytic activity through IFN- $\alpha$ release. Activated NK cells, in turn, can kill tumor cells, induce mDC maturation, and migration to draining lymph nodes, where mDCs can cross-present tumor antigens to CD8 T cells (69). Again, in this study, cross-priming of $\mathrm{CD}^{+} \mathrm{T}$ cells is exclusively NK celldependent, as NK cell depletion results in complete abrogation of $\mathrm{CD} 8^{+} \mathrm{T}$ cell priming. Therefore, it is likely that NK cells can favor cross-presentation by DCs, although the specific abilities of different DC subsets, as well as the mechanisms involved are still to be clearly identified. It is conceivable that NK cell killing of tumor cells could provide antigens subsequently taken up, processed, and cross-presented by DCs; at the same time, activation of NK cells is associated to the secretion of cytokines, such as TNF or IFN- $\gamma$, potentially able to help cross-priming of specific CTLs (Figure 2).

Thus, NK cells, upon interaction with DCs, can induce the activation of specific functions on DCs. Nevertheless, the capability of NK cells to induce DC activation is not the only mechanism by which NK cells may influence DC functions. Once activated by DCs, NK cells acquire the capability of killing immature, but not mature, $\mathrm{mDCs}(5)$. It has been proposed that more mature, activated DCs, by upregulating their surface expression of MHC class I molecules, would be protected from NK cell lysis. Conversely, immature DCs, expressing lower levels of MHC class I molecules, are more susceptible to NK cell killing. DCs that fail to express sufficient amounts of MHC class I molecules would induce inappropriate, low affinity $\mathrm{T}$ cell priming resulting either in Th2 response or in the induction of tolerance $(70,71)$. For these reasons, it was hypothesized that NK-mediated DC killing might represent a mechanism of DC selection for the control of downstream adaptive immune response (DC editing) (70). While in vivo evidence for DC activation by NK cells has extensively been provided, the direct demonstration that DC editing by NK cells also occurs in vivo, as well as its putative role in promoting an efficient immune response, has only recently been proven (72). In an experimental model of cancer cell vaccination, NK cells were necessary for removing less immunogenic DCs by a perforin-dependent mechanism, leading to an improved capability of residual DCs to induce anti-tumor CTL response and mice survival.

\section{CONCLUDING REMARIKS}

Studies performed in the last few years have clearly shown that, during immune response, different leukocytes act by not only displaying their own protective functions, but also interacting with each other to optimize the response against microorganisms and cancer cells. Recent identification of different DC subsets in the human system is leading to new insights in the field of innate cell interactions, particularly for the cross-talk occurring between these DC subsets and NK cells. As DC subsets show a specific distribution in human tissues, their interactions with NK cells should now be better dissected. Noteworthy, some light has also been recently shed regarding the distribution and trafficking of NK cells in the human body, thus allowing a more complete depiction of where these two cell types could physically interact. Interestingly, DC subsets are now emerging as cells endowed with peculiar functions, either in terms of specific cytokine secretion or of signals provided to other neighboring cells through distinctive surface molecules during cell-to-cell contacts. Therefore, NK/DC interactions should no longer be considered as the cross-talk between two homogeneous populations of innate cells but rather as a more complex network of cell subset cooperation acting in discrete regions of the body to fulfill complementary tasks.

\section{REFERENCES}

1. Moretta A, Bottino C, Mingari MC, Biassoni R, Moretta L. What is a natural killer cell? Nat Immunol (2002) 3(1):6-8. doi:10.1038/ni0102-6

2. Moretta A, Bottino C, Vitale M, Pende D, Cantoni C, Mingari MC, et al. Activating receptors and coreceptors involved in human natural killer cellmediated cytolysis. Annu Rev Immunol (2001) 19:197-223. doi:10.1146/ annurev.immunol.19.1.197

3. Moretta L, Moretta A. Killer immunoglobulin-like receptors. Curr Opin Immunol (2004) 16(5):626-33. doi:10.1016/j.coi.2004.07.010

4. Moretta L, Moretta A. Unravelling natural killer cell function: triggering and inhibitory human NK receptors. EMBO J (2004) 23(2):255-9. doi:10.1038/sj. emboj.7600019

5. Ferlazzo G, Tsang ML, Moretta L, Melioli G, Steinman RM, Munz C. Human dendritic cells activate resting natural killer (NK) cells and are recognized via the NKp30 receptor by activated NK cells. J Exp Med (2002) 195(3):343-51. doi:10.1084/jem.20011149

6. Piccioli D, Sbrana S, Melandri E, Valiante NM. Contact-dependent stimulation and inhibition of dendritic cells by natural killer cells. J Exp Med (2002) 195(3):335-41. doi:10.1084/jem.20010934

7. Bellora F, Castriconi R, Dondero A, Reggiardo G, Moretta L, Mantovani A, et al. The interaction of human natural killer cells with either unpolarized or polarized macrophages results in different functional outcomes. Proc Natl Acad Sci U S A (2010) 107(50):21659-64. doi:10.1073/pnas.1007654108

8. Cerboni C, Zingoni A, Cippitelli M, Piccoli M, Frati L, Santoni A. Antigenactivated human $\mathrm{T}$ lymphocytes express cell-surface NKG2D ligands via an ATM/ATR-dependent mechanism and become susceptible to autologous NKcell lysis. Blood (2007) 110(2):606-15. doi:10.1182/blood-2006-10-052720

9. Rabinovich BA, Li J, Shannon J, Hurren R, Chalupny J, Cosman D, et al. Activated, but not resting, T cells can be recognized and killed by syngeneic NK cells. J Immunol (2003) 170(7):3572-6.

10. Cooper MA, Fehniger TA, Caligiuri MA. The biology of human natural killer-cell subsets. Trends Immunol (2001) 22(11):633-40. doi:10.1016/S1471-4906(01) 02060-9

11. Fauriat C, Long EO, Ljunggren HG, Bryceson YT. Regulation of human NK-cell cytokine and chemokine production by target cell recognition. Blood (2010) 115(11):2167-76. doi:10.1182/blood-2009-08-238469

12. Banchereau J, Steinman RM. Dendritic cells and the control of immunity. Nature (1998) 392(6673):245-52. doi:10.1038/32588

13. O’Doherty U, Peng M, Gezelter S, Swiggard WJ, Betjes M, Bhardwaj N, et al. Human blood contains two subsets of dendritic cells, one immunologically mature and the other immature. Immunology (1994) 82(3):487-93.

14. Dzionek A, Fuchs A, Schmidt P, Cremer S, Zysk M, Miltenyi S, et al. BDCA-2, BDCA-3, and BDCA-4: three markers for distinct subsets of dendritic cells in human peripheral blood. J Immunol (2000) 165(11):6037-46. 
15. Huysamen C, Willment JA, Dennehy KM, Brown GD. CLEC9A is a novel activation C-type lectin-like receptor expressed on BDCA3+ dendritic cells and a subset of monocytes. J Biol Chem (2008) 283(24):16693-701. doi:10.1074/jbc. M709923200

16. Segura E, Valladeau-Guilemond J, Donnadieu MH, Sastre-Garau X, Soumelis $\mathrm{V}$, Amigorena S. Characterization of resident and migratory dendritic cells in human lymph nodes. J Exp Med (2012) 209(4):653-60. doi:10.1084/jem. 20111457

17. Summers KL, Hock BD, McKenzie JL, Hart DN. Phenotypic characterization of five dendritic cell subsets in human tonsils. Am J Pathol (2001) 159(1):285-95. doi:10.1016/S0002-9440(10)61694-X

18. Haniffa M, Shin A, Bigley V, McGovern N, Teo P, See P, et al. Human tissues contain CD141hi cross-presenting dendritic cells with functional homology to mouse $\mathrm{CD} 103^{+}$nonlymphoid dendritic cells. Immunity (2012) 37(1):60-73. doi:10.1016/j.immuni.2012.04.012

19. Nestle FO, Zheng XG, Thompson CB, Turka LA, Nickoloff BJ. Characterization of dermal dendritic cells obtained from normal human skin reveals phenotypic and functionally distinctive subsets. J Immunol (1993) 151(11):6535-45.

20. Klechevsky E, Morita R, Liu M, Cao Y, Coquery S, Thompson-Snipes L, et al. Functional specializations of human epidermal Langerhans cells and CD14+ dermal dendritic cells. Immunity (2008) 29(3):497-510. doi:10.1016/j.immuni. 2008.07.013

21. Morandi B, Bonaccorsi I, Mesiti M, Conte R, Carrega P, Costa G, et al. Characterization of human afferent lymph dendritic cells from seroma fluids. J Immunol (2013) 191(9):4858-66. doi:10.4049/jimmunol.1300760

22. Segura E, Amigorena S. Inflammatory dendritic cells in mice and humans. Trends Immunol (2013) 34(9):440-5. doi:10.1016/j.it.2013.06.001

23. Zhang AL, Colmenero P, Purath U, Teixeira de Matos C, Hueber W, Klareskog L, et al. Natural killer cells trigger differentiation of monocytes into dendritic cells. Blood (2007) 110(7):2484-93. doi:10.1182/blood-2007-02-076364

24. Carrega P, Ferlazzo G. Natural killer cell distribution and trafficking in human tissues. Front Immunol (2012) 3:347. doi:10.3389/fimmu.2012.00347

25. Gregoire C, Chasson L, Luci C, Tomasello E, Geissmann F, Vivier E, et al. The trafficking of natural killer cells. Immunol Rev (2007) 220:169-82. doi:10.1111/ j.1600-065X.2007.00563.x

26. Carrega P, Bonaccorsi I, Di Carlo E, Morandi B, Paul P, Rizzello V, et al. CD56 ${ }^{\text {bright }}$ perforin ${ }^{\text {low }}$ noncytotoxic human NK cells are abundant in both healthy and neoplastic solid tissues and recirculate to secondary lymphoid organs via afferent lymph. J Immunol (2014) 192(8):3805-15. doi:10.4049/ jimmunol.1301889

27. Montalto E, Mangraviti S, Costa G, Carrega P, Morandi B, Pezzino G, et al Seroma fluid subsequent to axillary lymph node dissection for breast cancer derives from an accumulation of afferent lymph. Immunol Lett (2010) 131(1):67-72. doi:10.1016/j.imlet.2010.03.002

28. Romagnani C, Juelke K, Falco M, Morandi B, D’Agostino A, Costa R, et al. CD56brightCD16- killer Ig-like receptor-NK cells display longer telomeres and acquire features of CD56dim NK cells upon activation. J Immunol (2007) 178(8):4947-55.

29. Trepel F. Number and distribution of lymphocytes in man. A critical analysis. Klin Wochenschr (1974) 52(11):511-5. doi:10.1007/BF01468720

30. Ferlazzo G, Thomas D, Lin SL, Goodman K, Morandi B, Muller WA, et al. The abundant NK cells in human secondary lymphoid tissues require activation to express killer cell Ig-like receptors and become cytolytic. J Immunol (2004) 172(3):1455-62.

31. Vitale M, Della Chiesa M, Carlomagno S, Romagnani C, Thiel A, Moretta $\mathrm{L}$, et al. The small subset of CD56brightCD16- natural killer cells is selectively responsible for both cell proliferation and interferon-gamma production upon interaction with dendritic cells. Eur J Immunol (2004) 34(6):1715-22. doi:10.1002/eji.200425100

32. Nizzoli G, Krietsch J, Weick A, Steinfelder S, Facciotti F, Gruarin P, et al. Human $\mathrm{CD} 1 \mathrm{c}+$ dendritic cells secrete high levels of IL-12 and potently prime cytotoxic T-cell responses. Blood (2013) 122(6):932-42. doi:10.1182/blood-201304-495424

33. Segura E, Durand M, Amigorena S. Similar antigen cross-presentation capacity and phagocytic functions in all freshly isolated human lymphoid organ-resident dendritic cells. J Exp Med (2013) 210(5):1035-47. doi:10.1084/jem.20121103

34. Meixlsperger S, Leung CS, Ramer PC, Pack M, Vanoaica LD, Breton G, et al. $\mathrm{CD} 141+$ dendritic cells produce prominent amounts of IFN-alpha after dsRNA recognition and can be targeted via DEC-205 in humanized mice. Blood (2013) 121(25):5034-44. doi:10.1182/blood-2012-12-473413

35. Zaba LC, Krueger JG, Lowes MA. Resident and “inflammatory" dendritic cells in human skin. J Invest Dermatol (2009) 129(2):302-8. doi:10.1038/jid. 2008.225

36. Banchereau J, Thompson-Snipes L, Zurawski S, Blanck JP, Cao Y, Clayton S, et al. The differential production of cytokines by human Langerhans cells and dermal CD14(+) DCs controls CTL priming. Blood (2012) 119(24):5742-9. doi:10.1182/blood-2011-08-371245

37. Banchereau J, Briere F, Caux C, Davoust J, Lebecque S, Liu YJ, et al. Immunobiology of dendritic cells. Annu Rev Immunol (2000) 18:767-811. doi:10.1146/ annurev.immunol.18.1.767

38. Steinman RM. The dendritic cell system and its role in immunogenicity. Annu Rev Immunol (1991) 9:271-96. doi:10.1146/annurev.iy.09.040191.001415

39. Lucas M, Schachterle W, Oberle K, Aichele P, Diefenbach A. Dendritic cells prime natural killer cells by trans-presenting interleukin 15. Immunity (2007) 26(4):503-17. doi:10.1016/j.immuni.2007.03.006

40. Kassim SH, Rajasagi NK, Zhao X, Chervenak R, Jennings SR. In vivo ablation of CD11c-positive dendritic cells increases susceptibility to herpes simplex virus type 1 infection and diminishes NK and T-cell responses. J Virol (2006) 80(8):3985-93. doi:10.1128/JVI.80.8.3985-3993.2006

41. Andrews DM, Scalzo AA, Yokoyama WM, Smyth MJ, Degli-Esposti MA. Functional interactions between dendritic cells and NK cells during viral infection. Nat Immunol (2003) 4(2):175-81. doi:10.1038/ni880

42. Fernandez NC, Lozier A, Flament C, Ricciardi-Castagnoli P, Bellet D, Suter M, et al. Dendritic cells directly trigger NK cell functions: cross-talk relevant in innate anti-tumor immune responses in vivo. Nat Med (1999) 5(4):405-11. doi:10.1038/7403

43. Walzer T, Dalod M, Robbins SH, Zitvogel L, Vivier E. Natural-killer cells and dendritic cells: "l'union fait la force." Blood (2005) 106(7):2252-8. doi:10.1182/ blood-2005-03-1154

44. Biron CA, Nguyen KB, Pien GC, Cousens LP, Salazar-Mather TP. Natural killer cells in antiviral defense: function and regulation by innate cytokines. Annu Rev Immunol (1999) 17:189-220. doi:10.1146/annurev.immunol.17.1.189

45. Nguyen KB, Salazar-Mather TP, Dalod MY, Van Deusen JB, Wei XQ, Liew FY, et al. Coordinated and distinct roles for IFN-alpha beta, IL-12, and IL-15 regulation of NK cell responses to viral infection. J Immunol (2002) 169(8): 4279-87.

46. Munz C, Dao T, Ferlazzo G, de Cos MA, Goodman K, Young JW. Mature myeloid dendritic cell subsets have distinct roles for activation and viability of circulating human natural killer cells. Blood (2005) 105(1):266-73. doi:10.1182/blood-2004-06-2492

47. Borg C, Jalil A, Laderach D, Maruyama K, Wakasugi H, Charrier S, et al. NK cell activation by dendritic cells (DCs) requires the formation of a synapse leading to IL-12 polarization in DCs. Blood (2004) 104(10):3267-75. doi:10.1182/blood-2004-01-0380

48. Pallandre JR, Krzewski K, Bedel R, Ryffel B, Caignard A, Rohrlich PS, et al. Dendritic cell and natural killer cell cross-talk: a pivotal role of CX3CL1 in NK cytoskeleton organization and activation. Blood (2008) 112(12):4420-4. doi:10.1182/blood-2007-12-126888

49. Draghi M, Pashine A, Sanjanwala B, Gendzekhadze K, Cantoni C, Cosman D, et al. NKp46 and NKG2D recognition of infected dendritic cells is necessary for NK cell activation in the human response to influenza infection. J Immunol (2007) 178(5):2688-98

50. Gerosa F, Gobbi A, Zorzi P, Burg S, Briere F, Carra G, et al. The reciprocal interaction of NK cells with plasmacytoid or myeloid dendritic cells profoundly affects innate resistance functions. J Immunol (2005) 174(2):727-34.

51. Della Chiesa M, Romagnani C, Thiel A, Moretta L, Moretta A. Multidirectional interactions are bridging human NK cells with plasmacytoid and monocyte-derived dendritic cells during innate immune responses. Blood (2006) 108(12):3851-8. doi:10.1182/blood-2006-02-004028

52. Perrot I, Deauvieau F, Massacrier C, Hughes N, Garrone P, Durand I, et al. TLR3 and Rig-like receptor on myeloid dendritic cells and Rig-like receptor on human NK cells are both mandatory for production of IFN-gamma in response to double-stranded RNA. J Immunol (2010) 185(4):2080-8. doi:10. 4049/jimmunol.1000532

53. Ferlazzo G, Pack M, Thomas D, Paludan C, Schmid D, Strowig T, et al. Distinct roles of IL-12 and IL-15 in human natural killer cell activation by dendritic 
cells from secondary lymphoid organs. Proc Natl Acad Sci U S A (2004) 101(47):16606-11. doi:10.1073/pnas.0407522101

54. Gerosa F, Baldani-Guerra B, Nisii C, Marchesini V, Carra G, Trinchieri G. Reciprocal activating interaction between natural killer cells and dendritic cells. J Exp Med (2002) 195(3):327-33. doi:10.1084/jem.20010938

55. Mailliard RB, Son YI, Redlinger R, Coates PT, Giermasz A, Morel PA, et al. Dendritic cells mediate NK cell help for Th1 and CTL responses: two-signal requirement for the induction of NK cell helper function. J Immunol (2003) 171(5):2366-73.

56. Agaugue S, Marcenaro E, Ferranti B, Moretta L, Moretta A. Human natural killer cells exposed to IL-2, IL-12, IL-18, or IL-4 differently modulate priming of naive T cells by monocyte-derived dendritic cells. Blood (2008) 112(5):1776-83. doi:10.1182/blood-2008-02-135871

57. Morandi B, Mortara L, Carrega P, Cantoni C, Costa G, Accolla RS, et al. $\mathrm{NK}$ cells provide helper signal for $\mathrm{CD} 8+\mathrm{T}$ cells by inducing the expression of membrane-bound IL-15 on DCs. Int Immunol (2009) 21(5):599-606. doi:10.1093/intimm/dxp029

58. Vitale M, Della Chiesa M, Carlomagno S, Pende D, Arico M, Moretta L, et al. NK-dependent DC maturation is mediated by TNFalpha and IFNgamma released upon engagement of the NKp30 triggering receptor. Blood (2005) 106(2):566-71. doi:10.1182/blood-2004-10-4035

59. Mocikat R, Braumuller H, Gumy A, Egeter O, Ziegler H, Reusch U, et al. Natural killer cells activated by MHC class I(low) targets prime dendritic cells to induce protective CD8 T cell responses. Immunity (2003) 19(4):561-9. doi:10.1016/S1074-7613(03)00264-4

60. Munz C, Steinman RM, Fujii S. Dendritic cell maturation by innate lymphocytes: coordinated stimulation of innate and adaptive immunity. J Exp Med (2005) 202(2):203-7. doi:10.1084/jem.20050810

61. Robbins SH, Bessou G, Cornillon A, Zucchini N, Rupp B, Ruzsics Z, et al. Natural killer cells promote early CD8 T cell responses against cytomegalovirus. PLoS Pathog (2007) 3(8):e123. doi:10.1371/journal.ppat.0030123

62. Nandakumar S, Woolard SN, Yuan D, Rouse BT, Kumaraguru U. Natural killer cells as novel helpers in anti-herpes simplex virus immune response. J Virol (2008) 82(21):10820-31. doi:10.1128/JVI.00365-08

63. Adam C, King S, Allgeier T, Braumuller H, Luking C, Mysliwietz J, et al. DC-NK cell cross talk as a novel CD4+ T-cell-independent pathway for antitumor CTL induction. Blood (2005) 106(1):338-44. doi:10.1182/blood-2004-09-3775

64. Combe CL, Curiel TJ, Moretto MM, Khan IA. NK cells help to induce CD8(+)T-cell immunity against Toxoplasma gondii in the absence of CD4(+) T cells. Infect Immun (2005) 73(8):4913-21. doi:10.1128/IAI.73.8.4913-4921.2005

65. Albert ML, Sauter B, Bhardwaj N. Dendritic cells acquire antigen from apoptotic cells and induce class I-restricted CTLs. Nature (1998) 392(6671):86-9. doi: $10.1038 / 32183$
66. Iyoda T, Shimoyama S, Liu K, Omatsu Y, Akiyama Y, Maeda Y, et al. The CD8+ dendritic cell subset selectively endocytoses dying cells in culture and in vivo. J Exp Med (2002) 195(10):1289-302. doi:10.1084/jem.20020161

67. Dao T, Gomez-Nunez M, Antczak C, Kappel B, Jaggi JS, Korontsvit T, et al. Natural killer cells license dendritic cell cross-presentation of B lymphoma cell - associated antigens. Clin Cancer Res (2005) 11(24 Pt 1):8763-72. doi:10.1158/1078-0432.CCR-05-0975

68. Tosi D, Valenti R, Cova A, Sovena G, Huber V, Pilla L, et al. Role of crosstalk between IFN-alpha-induced monocyte-derived dendritic cells and NK cells in priming $\mathrm{CD} 8+\mathrm{T}$ cell responses against human tumor antigens. J Immunol (2004) 172(9):5363-70.

69. Liu C, Lou Y, Lizee G, Qin H, Liu S, Rabinovich B, et al. Plasmacytoid dendritic cells induce NK cell-dependent, tumor antigen-specific $\mathrm{T}$ cell crosspriming and tumor regression in mice. J Clin Invest (2008) 118(3):1165-75. doi:10.1172/JCI33583

70. Moretta A. Natural killer cells and dendritic cells: rendezvous in abused tissues. Nat Rev Immunol (2002) 2(12):957-64. doi:10.1038/nri956

71. Langenkamp A, Messi M, Lanzavecchia A, Sallusto F. Kinetics of dendritic cell activation: impact on priming of $\mathrm{TH} 1, \mathrm{TH} 2$ and nonpolarized $\mathrm{T}$ cells. Nat Immunol (2000) 1(4):311-6. doi:10.1038/79758

72. Morandi B, Mortara L, Chiossone L, Accolla RS, Mingari MC, Moretta L, et al. Dendritic cell editing by activated natural killer cells results in a more protective cancer-specific immune response. PLoS One (2012) 7(6):e39170. doi:10.1371/journal.pone.0039170

Conflict of Interest Statement: The Review Editor Mariella Della Chiesa declares that, despite being affiliated to the same institution as author Barbara Morandi, the review process was handled objectively and no conflict of interest exists. The authors declare that the research was conducted in the absence of any commercial or financial relationships that could be construed as a potential conflict of interest.

Received: 29 January 2014; accepted: 26 March 2014; published online: 10 April 2014. Citation: Ferlazzo $G$ and Morandi $B$ (2014) Cross-talks between natural killer cells and distinct subsets of dendritic cells. Front. Immunol. 5:159. doi: 10.3389/fimmu.2014.00159

This article was submitted to NK Cell Biology, a section of the journal Frontiers in Immunology.

Copyright (0) 2014 Ferlazzo and Morandi. This is an open-access article distributed under the terms of the Creative Commons Attribution License (CC BY). The use, distribution or reproduction in other forums is permitted, provided the original author $(s)$ or licensor are credited and that the original publication in this journal is cited, in accordance with accepted academic practice. No use, distribution or reproduction is permitted which does not comply with these terms. 